\title{
Original
}

\section{A New Method to Measure and Assess Tooth Size and Tooth Size Discrepancy Via Circumferential Measurements using Stereomicroscope}

\author{
Fazal Shahid $^{1)}$, Mohammad Khursheed Alam ${ }^{1)}$, Mohd Fadhli Khamis ${ }^{2)}$, Atsuo Komori ${ }^{3)}$, \\ Katsutoshi Kubo ${ }^{3)}$ and Hatsuhiko Maeda ${ }^{3)}$
}

\author{
1) Orthodontic Unit, School of Dental Science, Universiti Sains Malaysia, Kelantan, Malaysia \\ 2) Forensic Dentistry Unit, School of Dental Science, Universiti Sains Malaysia, Kelantan, Malaysia \\ 3) Department of Oral Pathology, School of Dentistry, Aichi Gakuin University, Nagoya, Japan \\ (Accepted for publication, July 13, 2015)
}

\begin{abstract}
An accurate evaluation of tooth size and tooth size discrepancy is critically important in orthodontic diagnosis and treatment planning. The purpose of this study was to establish a new method to measure and assess tooth size and tooth size discrepancy with accuracy and reproducibility, named as circumferential tooth size (CFT), circumferential anterior tooth size ratio (CAR), circumferential overall tooth size ratio (COR) respectively. Total 128 dental models were scanned via Hirox digital stereomicroscope for the fabrication of the digital models. Dental models were selected on the basis of inclusion criteria. All the measurements were obtained with the accuracy of $0.1 \times 10^{-6} \mathrm{~mm}$; the mean and the SD for the CFT, CAR and COR were calculated. The developed norms for the CFT, demonstrated significantly greater values for males in relation to females. More precisely, there were statistically significant differences observed in different variables $\left({ }^{*} \mathrm{p} \leqq 0.05\right.$ to $* * * p \leqq 0.001)$. CAR and COR ratio show slight greater value for males without any statistically significant differences. The findings provide valuable information that CFT cover the tooth size in all dimensional aspects. For the prediction of ideal occlusion to be achieved at the finishing stage, orthodontist needs to evaluate CAR and COR ratios via proposed method.
\end{abstract}

Key words: Circumferential tooth size, Tooth size discrepancy, Digital dental models.

\section{Introduction}

In orthodontic diagnosis and treatment planning, great importance has been attached to evaluating the tooth size and tooth size discrepancy. Linear measurements have been incorporated into various dental model analyses to help the clinician to measure the tooth size and tooth size discrepancies to establish the most appropriate treatment plan $^{1-3)}$.

Variations in tooth size and tooth size ratio have been connected with diverse ethnic foundations and occlusion status ${ }^{4-}$ 9). Inter maxillary tooth size discrepancy is not infrequent in many populations ${ }^{1,10,11)}$. From a clinical point of view, ideal balance ought to exist between the mesiodistal tooth sizes of the maxillary and mandibular arches to assure correct interdigitation, overbite and overjet at the consummation of orthodontic treatment ${ }^{12-14)}$.

The time in which the orthodontic practice is currently being known as "digital era" the computerized advances are no doubt used to resolve the past confinement of the patient record keeping

Correspondence to: Dr. Mohammad Khursheed Alam, Orthodontic Unit, School of Dental Science, Universiti Sains Malaysia, Kubang Kerian, 16150 Kota Bharu, Kelantan, Malaysia; Tel: +60142926987; Email: dralam@gmail.com,dralam@usm.my and management $\mathrm{t}^{15}$. Digital models have facilitated the automated calculation of tooth size ratios once the mesial and distal points of each tooth have been identified ${ }^{16-21)}$. Digital models have advantages of being faster and providing easier storage of data ${ }^{14,}$ ${ }^{22)}$. Digital study models have been found to be an appropriate alternative to those derived using plaster models and digital calipers $^{14,16-18,23)}$.

Analysis of tooth size discrepancy ${ }^{24,25)}$ is of extraordinary importance for orthodontic diagnosis and treatment planning and considered as a seventh "key" to occlusion" ${ }^{26)}$. Some studies investigated race and sex differences ${ }^{1,5}$. Other authors have suggested no significant differences in the tooth size ratio with different malocclusion ${ }^{10,27,28)}$.

A specific measurement should assess the tooth size and tooth size discrepancy, independent of mesiodistal, buccolingual and diagonal linear measurements. Our study investigated a new method to measure the tooth size and tooth size discrepancy and named as circumferential tooth size (CFT), circumferential anterior tooth size ratio (CAR), circumferential overall tooth size ratio (COR) respectively. CFT, CAR and COR do not depend on any 


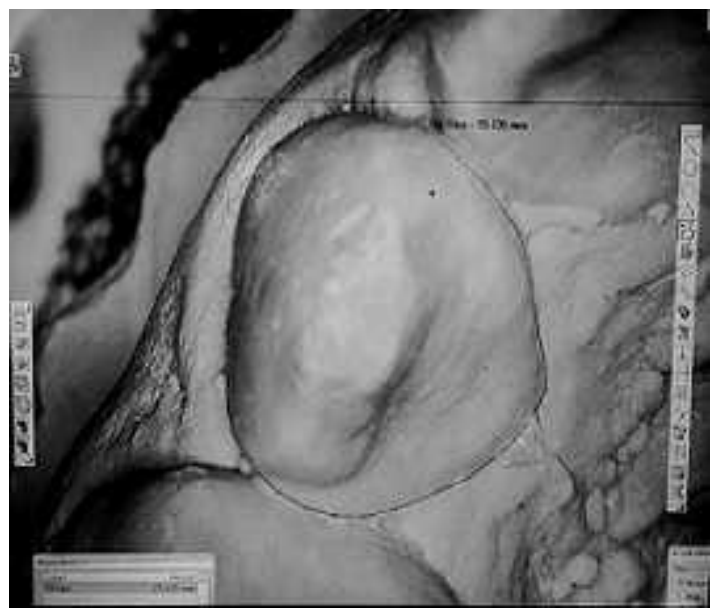

Figure 1. Circumferential tooth size measurement

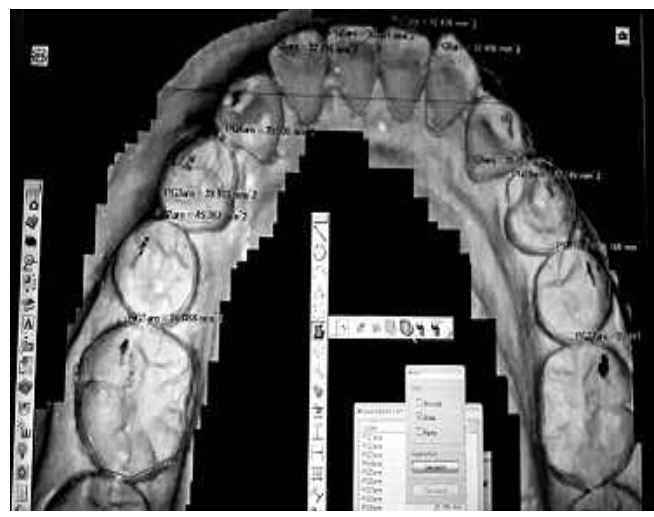

Figure 3. Fabrication of the digital models via hirox digital stereomicroscope and circumferential tooth size measurements

linear measurement, CFT would be especially valuable whenever previously established tooth size measurements, such as the mesiodistal, buccolingual and diagonal cannot be used accurately because of their dependence on varying factors like caries and tooth wear.

\section{The CFT, CAR and COR}

The CFT, CAR and COR are the new measurements for assessing the tooth size and tooth size discrepancy of the maxilla and the mandible via digital dental models.

\section{CFT}

The CFT can be found by locating the maximum perimeter of the tooth (Fig. 1).

\section{CAR and COR}

The CAR and COR can be used to identify the tooth size discrepancy. For CFT in orthodontics CAR and COR can be obtained by the following formula

$$
\mathrm{CAR}=\frac{\text { sum of CFT mandibular } 3 \text { to } 3}{\text { sum of CFT maxillary } 3 \text { to } 3} \times 100
$$

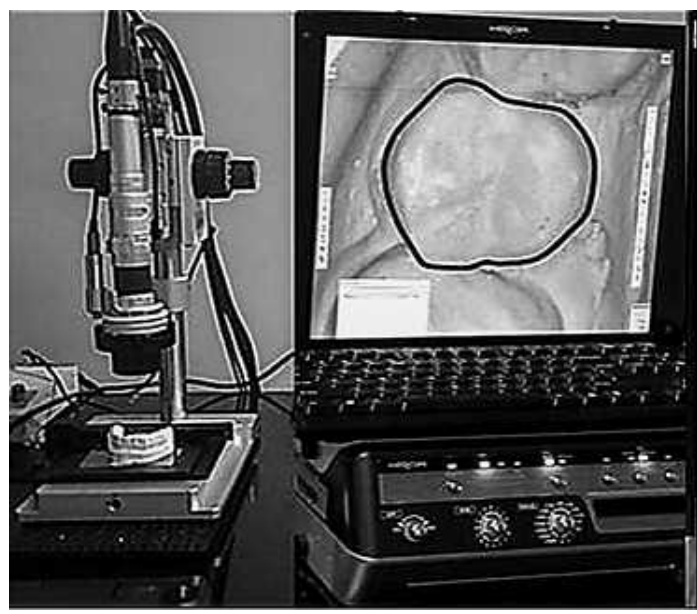

Figure 2. Hirox digital stereomicroscope

$$
\text { COR }=\frac{\text { sum of CFT mandibular } 6 \text { to } 6}{\text { sum of CFT maxillary } 6 \text { to } 6} \times 100
$$

The purposes of this study were to establish the norms for Pakistani population with regard to CFT, CAR and COR using stereomicroscopic digital dental models. In addition to the norms of circumferential dimensions and ratios, the sex and side differences were also investigated.

\section{Materials and Methods}

Dental impression and personal information were collected only after informed consent has been obtained from the subjects. This study was approved by the Human Ethics Committee of the Universiti Sains Malaysia (USM). Current research was outlined and directed as indicated by the rules of strengthening the Reporting of Observational studies in Epidemiology (STROBE), and we used the STROBE guidelines in this manuscript ${ }^{29}$.

\section{Sample size calculation}

Sample size were calculated based on our pilot study by using PS software ${ }^{30)}$. The parameters were as follow: power 0.8 , significant level 0.05 , standard deviation (from the pilot study) $1.8 \mathrm{~mm}$, mean difference $0.9 \mathrm{~mm}$ and equal ratio between groups. The estimated sample size was 64 females and 64 males. Three thousand five hundred eighty-four variables were measured with the following inclusion and exclusion criteria.

\section{Inclusion criteria}

The inclusion criteria include healthy subjects with age between $18-24$ years, having full dentition in both arches excluding the third molars, no history of orthodontic treatment, ideal occlusions with class I incisor relationship according to British standards institute, class I molar and canine relationship, no crowding, no spacing, no rotations along with good quality study models for digital scanning and acquisitions were selected. 
Fazal Shahid et al.: Tooth Size Discrepancy Via Circumferential Measurements

Table 1. Norms based Circumferential Tooth Size Measurements

\begin{tabular}{|c|c|c|c|c|c|c|c|c|c|}
\hline \multirow[t]{2}{*}{ Variables* } & \multicolumn{2}{|c|}{ Male } & \multicolumn{2}{|c|}{ Female } & \multirow[b]{2}{*}{ Mean diff. } & \multicolumn{2}{|c|}{$95 \% \mathrm{CI}$} & \multirow[t]{2}{*}{$\mathrm{P}$} & \\
\hline & Mean & $\mathrm{SD}$ & Mean & SD & & Lower & Upper & & \\
\hline 11 & 27.24 & 1.82 & 25.75 & 1.73 & 1.49 & 0.89 & 2.09 & .001 & $* * *$ \\
\hline 12 & 22.47 & 1.78 & 21.52 & 1.84 & 0.95 & 0.35 & 1.56 & .002 & $* *$ \\
\hline 13 & 25.60 & 1.75 & 24.41 & 1.79 & 1.20 & 0.60 & 1.79 & .001 & $* * *$ \\
\hline 14 & 27.35 & 2.02 & 26.24 & 1.94 & 1.10 & 0.44 & 1.77 & .001 & $* * *$ \\
\hline 15 & 26.76 & 1.84 & 25.50 & 2.10 & 1.26 & 0.60 & 1.92 & .001 & $* * *$ \\
\hline 16 & 37.32 & 2.31 & 35.88 & 1.73 & 1.43 & 0.74 & 2.12 & .001 & $* * *$ \\
\hline 17 & 31.98 & 2.91 & 29.92 & 3.02 & 2.06 & 1.06 & 3.06 & .001 & $* * *$ \\
\hline 21 & 27.24 & 1.82 & 25.75 & 1.73 & 1.49 & 0.89 & 2.09 & .001 & $* * *$ \\
\hline 22 & 22.47 & 1.78 & 21.52 & 1.84 & 0.95 & 0.35 & 1.56 & .002 & $* *$ \\
\hline 23 & 25.60 & 1.75 & 24.41 & 1.79 & 1.20 & 0.60 & 1.79 & .001 & $* * *$ \\
\hline 24 & 27.34 & 2.02 & 26.24 & 1.94 & 1.10 & 0.43 & 1.77 & .001 & $* * *$ \\
\hline 25 & 26.76 & 1.83 & 25.50 & 2.10 & 1.26 & 0.60 & 1.92 & .001 & $* * *$ \\
\hline 26 & 37.32 & 2.31 & 35.88 & 1.73 & 1.43 & 0.74 & 2.12 & .001 & $* * *$ \\
\hline 27 & 31.98 & 2.91 & 29.92 & 3.02 & 2.06 & 1.06 & 3.06 & .001 & $* * *$ \\
\hline 31 & 19.32 & 1.54 & 18.34 & 1.64 & 0.99 & 0.45 & 1.52 & .001 & $* * *$ \\
\hline 32 & 20.12 & 1.36 & 18.97 & 1.49 & 1.15 & 0.67 & 1.63 & .001 & $* * *$ \\
\hline 33 & 23.08 & 1.44 & 21.48 & 1.84 & 1.60 & 1.05 & 2.15 & .001 & $* * *$ \\
\hline 34 & 23.90 & 1.68 & 23.02 & 1.81 & 0.89 & 0.30 & 1.47 & .003 & $* *$ \\
\hline 35 & 25.34 & 1.55 & 24.43 & 2.11 & 0.91 & 0.29 & 1.53 & .004 & $* *$ \\
\hline 36 & 36.18 & 2.30 & 34.18 & 4.08 & 2.00 & 0.91 & 3.09 & .001 & $* * *$ \\
\hline 37 & 33.57 & 2.64 & 32.38 & 2.26 & 1.19 & 0.36 & 2.02 & .005 & $* *$ \\
\hline 41 & 19.32 & 1.54 & 18.34 & 1.64 & 0.99 & 0.45 & 1.52 & .001 & $* * *$ \\
\hline 42 & 20.12 & 1.36 & 18.97 & 1.49 & 1.15 & 0.67 & 1.63 & .001 & $* * *$ \\
\hline 43 & 23.08 & 1.44 & 21.48 & 1.84 & 1.60 & 1.05 & 2.15 & .001 & $* * *$ \\
\hline 44 & 23.90 & 1.68 & 23.02 & 1.81 & 0.89 & 0.30 & 1.47 & .003 & $* *$ \\
\hline 45 & 25.34 & 1.55 & 24.43 & 2.11 & 0.91 & 0.29 & 1.52 & .004 & $* *$ \\
\hline 46 & 36.18 & 2.30 & 34.18 & 4.08 & 2.00 & 0.91 & 3.09 & .001 & $* * *$ \\
\hline 47 & 33.57 & 2.64 & 32.38 & 2.26 & 1.19 & 0.36 & 2.02 & .005 & $* *$ \\
\hline
\end{tabular}

*FDI notation; CI: confidence interval; SD: standard deviation; Mean diff.: mean differences $\left({ }^{* * *} \mathrm{p} \leqq 0.001\right),(* * \mathrm{p} \leqq 0.01)$ and $\left({ }^{*} \mathrm{p} \leqq 0.05\right)$.

Table 2. Right and Left Comparison for Circumferential Measurements

\begin{tabular}{|c|c|c|c|c|c|c|c|c|c|c|}
\hline \multirow{3}{*}{ variables } & \multicolumn{5}{|c|}{ Maxilla } & \multirow{3}{*}{ Mean diff. } & \multirow{3}{*}{ SD } & \multicolumn{3}{|c|}{ Mandible } \\
\hline & \multirow[t]{2}{*}{ Mean diff. } & \multirow[t]{2}{*}{ SD } & \multicolumn{2}{|c|}{$95 \% \mathrm{CI}$} & \multirow[t]{2}{*}{$\mathrm{P}$} & & & \multicolumn{2}{|c|}{$95 \% \mathrm{CI}$} & \multirow[t]{2}{*}{$\mathrm{P}$} \\
\hline & & & Lower & Upper & & & & Lower & Upper & \\
\hline CI & 0.01 & .004 & -.001 & .001 & .946 & 0.01 & .002 & -.001 & .000 & .224 \\
\hline LI & 0.01 & .005 & .000 & .001 & .303 & 0.01 & .002 & .000 & .001 & .258 \\
\hline CI & 0.01 & .004 & -.001 & .001 & .963 & 0.01 & .004 & .000 & .001 & .221 \\
\hline IPM & 0.01 & .007 & -.001 & .002 & .584 & 0.01 & .003 & -.001 & .000 & .328 \\
\hline $2 \mathrm{PM}$ & 0.01 & .002 & -.001 & .000 & .504 & 0.01 & .003 & -.001 & .000 & .151 \\
\hline IM & 0.01 & .002 & -.001 & .000 & .028 & 0.01 & .003 & .000 & .001 & .741 \\
\hline $2 \mathrm{M}$ & 0.01 & .003 & -.001 & .000 & .392 & 0.01 & .003 & -.001 & .000 & .106 \\
\hline
\end{tabular}

CI: central incisor; LI: lateral incisor; C: canine; IPM: $1^{\text {st }}$ premolar; 2PM: $2^{\text {nd }}$ premolar; IM: $1^{\text {st }}$ molar; $2 \mathrm{M}$ : $2^{\text {nd }}$ molar;

CI: confidence interval; Mean diff.: mean differences; SD: standard deviation. 
J.Hard Tissue Biology Vol. 24(4):305 -310, 2015

Table 3. CAR and COR Ratios with Sexual Dimorphism.

\begin{tabular}{llllllll}
\hline & Sex & Mean & SD & SE & \multicolumn{2}{c}{$95 \% \mathrm{CI}$} & \\
& & & & & Lower & Upper & $\mathrm{p}$ \\
\hline CAR & $\mathrm{M}$ & 83.09 & 3.52 & 0.41 & & & \\
& $\mathrm{~F}$ & 82.05 & 4.01 & 0.50 & -0.23 & 2.30 & 0.107 \\
$\mathrm{COR}$ & $\mathrm{M}$ & 88.79 & 3.13 & 0.36 & & & \\
& $\mathrm{~F}$ & 88.16 & 5.27 & 0.66 & -0.80 & 2.06 & 0.385 \\
\hline
\end{tabular}

CAR: circumferential anterior ratio; COR: circumferential overall ration; CI: confidence interval;

SD: standard deviation; SE: standard error mean.

\section{Exclusion criteria}

Subject who have inter proximal caries or restoration, missing or supernumerary teeth, teeth wear that affect the tooth size measurement and damage casts were excluded. Dental impressions of the upper and lower arches of the each subject were taken with alginate impression material (Zhermack Orthoprint alginate ISO 1563 -ADA 18 made in Italy) and poured with dental stone (Type III hard plaster quick stone made in China) in accordance with the manufacturer's instructions and labeled accordingly.

\section{Error study}

$20 \%$ of dental cast were randomly selected for intra observer errors. The time interval between the first and second reading were approximately 2 weeks. The method error was analyzed by the Dahlberg's double determination formula ${ }^{31)} . \mathrm{ME}=\Sigma\left(\mathrm{x}_{1}-\mathrm{x}_{2}\right)$ $2 / 2 n ; n=$ number of sample.

\section{Measurement of CFT}

Dental models of each subject for maxillary and mandibular arches were scanned via Hirox digital stereomicroscope (HIROX KH7700, Japan) for the fabrication of the digital models. CFT were carried out via stereomicroscope (SM) scanned digital models for maxillary and mandibular arches (Figs. 2 and 3). SM was proven as valid ${ }^{19)}$ and reliable tool for such measurements with the accuracy of $0.1 \times 10^{-6} \mathrm{~mm}$.

\section{Statistical analysis}

Data collected by the investigators were first entered into Excel (Microsoft, Redmond, Washington, USA). Collected data were screened for any missing values or outliers and for validity of distribution assumptions. To summarize the data, means and standard deviations of CFT were calculated. An independent samples t-test was used to evaluate differences for CFT in males and females. The paired sample $t$ test was used to determine differences in teeth size between the right and left side of the maxillary and mandibular arches. A P value $\leqq 0.05$ was considered to be statistically significant. All statistical analyses were performed in SPSS (IBM SPSS Statistics Version 22.0, Chicago, USA).

\section{Results}

\section{Error of the method}

The method error was analyzed by the Dalhberg's double determination formula, showed the value of $0.973 \mathrm{~mm}$ for CFT. The combined error for any of the variables was small and considered to be within acceptable limit ${ }^{31)}$.

\section{CFT norms and inter sex disparities}

Table 1 shows CFT comparisons between males and females using stereomicroscopic digital models. The developed norms for the CFT, demonstrated with significantly greater values for males in relation to females. More precisely, there were statistically significant differences observed in different variables $\left({ }^{*} \mathrm{p} \leqq 0.05\right.$ to $* * * \mathrm{p} \leqq 0.001)$.

\section{CFT comparison sides disparities for the maxillary and mandibular teeth}

Table 2 shows disparities between the right and left side for the CFT maxillary and mandibular teeth size. There were no statistically significant differences observed in all variables.

\section{CAR and COR ratio and inter sex disparities}

Table 3 shows CAR and COR ratio norms with slight greater value for males without any statistically significant differences.

\section{Discussion}

In orthodontic diagnosis and treatment planning, the evaluation of the tooth size and tooth size discrepancy is an indispensable step and this investigation is generally determined by study model analysis. To evaluate this relationship, various linear measurements by sliding calipers and digital models have been used ${ }^{3,14,16-19)}$. Digital dental models were considered as a valid and reliable tool for different tooth size measurements ${ }^{17,19,20,32)}$. Tooth size measurements were done with the accuracy of $1 \times 10^{-2} \mathrm{~mm}$ using digital caliper on the plaster models, emodels, and anatomodels and suresmile software with $0.1 \mathrm{~mm}^{33}$ the current study SM digital models is with the accuracy of $0.1 \times 10^{-6} \mathrm{~mm}$ which is a valid tool $^{19)}$.

The most popular parameter for assessing the tooth size and 
Fazal Shahid et al.: Tooth Size Discrepancy Via Circumferential Measurements

tooth size discrepancy remains the mesiodistal tooth width, but it is affected by various factors and can often be misleading. When using the mesiodistal tooth width, factors such as the patient's age, attrition and time consumption, which makes the interpretation of this tooth size and tooth size discrepancy much more complex. To overcome these problems, investigator measured the tooth size via mesiodistal ${ }^{1,12)}$, buccolingual ${ }^{34)}$ and diagonal crown diameters ${ }^{35)}$. Current study investigated the tooth size via CFT to assess the tooth size via alternate method. Tooth size may assume an imperative part in the etiology of malocclusions, should be considered for various analyses in orthodontic examination and treatment $^{5}$. Thus CFT is the alternate way to measure the tooth size from different perspective to help in the examination and treatment planning. The proposed CFT values will be of great importance in orthodontics for the ideal treatment to finish with proper interdigitation, overbite and overjet.

Nature has given a perfect proportion for teeth to occlude in proper relation. These relations were explored by means of mesial distal tooth estimate by Bolton ${ }^{24,25}$. In orthodontic diagnosis and treatment planning tooth size ratio is of extreme value. Some studies reflect that various tooth-size ratios show indigenous and sex differences ${ }^{1,8)}$. Others found no significant differences in either anterior or overall ratios in subjects with different malocclusion ${ }^{27,28)}$. Investigator in addition offered the newest formula for tooth size discrepancy ${ }^{36}$. Current study investigated the tooth size ratio via CFT for CAR and COR which is an alternate novel method to assess the tooth size discrepancy in orthodontics. CAR and COR showed no significant differences in relation to gender. In reality, without perfect proportional relationships in the circumferential tooth size, we cannot give ideal occlusion to the patients at the finishing stage of orthodontics treatment.

Human teeth have lots of variations in size in relation to race and $\operatorname{sex}^{37,38)}$. Tooth size disproportion is the lack of accord between the intermaxillary tooth size or group of teeth. Any disharmony in the tooth size can lead to either spacing in one arch or effect the functional relationship. To achieve an ideal occlusion the teeth size should be in ideal relation from all dimensions, such as mesiodistal, buccolingual and diagonal tooth size. The CFT cover the tooth size in all dimensional aspects. Thus for the accomplishment of good occlusion with the accurate overbite and overjet, the maxillary and mandibular teeth must be proportional in size form all dimensional aspects. For the prediction of ideal occlusion to be achieved at the finishing stage, orthodontist needs to evaluate CAR and COR ratios via proposed method. Current study investigated the tooth size and tooth size discrepancies for both sexes.

CFT, CAR and COR norms will be of great value in forensic dentistry and dental anthropology investigations in addition to orthodontic treatment planning. CFT, CAR and COR need to be further investigated on other population for sexual dimorphism.
In conclusion the, norms were developed for CFT using stereomicroscopic digital models; there is no difference between the CFT of right and left side of the maxillary and mandibular arches; norms were developed for the CAR and COR ratio to assess tooth size discrepancy; CFT presented the sexual dimorphism with the greatest value for male were observed; the developed norms CAR and COR ratios will be helpful adjunct in orthodontic treatment planning for understanding the tooth size discrepancies.

\section{Acknowledgement}

The authors would like to acknowledge the support from the Universiti Sains Malaysia 304/PPSG/61313104 short-term grant.

\section{References}

1. Alam MK and Iida J. Overjet, overbite and dental midline shift as predictors of tooth size discrepancy in a Bangladeshi population and a graphical overview of global tooth size ratios. Acta Odontol Scand 71: 1520-1531, 2013

2. Kansal A, Kittur N and Keluskar KM. Analysis of Bolton's ratio among different malocclusion groups: A hospital based study. Ind J Dent 3: 139-144, 2012

3. O'Mahony G, Millett DT, Barry MK, McIntyre GT and Cronin MS. Tooth size discrepancies in Irish orthodontic patients among different malocclusion groups. Angle Orthod 81: 130-133, 2011

4. Yonezu T, Warren JJ, Bishara SE and Steinbock KL. Comparison of tooth size and dental arch widths in contemporary Japanese and American preschool children. World J Orthod 2: 356-360, 2001

5. Lavelle C. Maxillary and mandibular tooth size in different racial groups and in different occlusal categories. Am J Orthod 61: 29-37, 1972

6. Smith SS, Buschang PH and Watanabe E. Interarch tooth size relationships of 3 populations:"Does Bolton's analysis apply?". Am J Orthod Dentofac Orthop 117: 169-174, 2000

7. Ta TA, Ling JY and Hägg U. Tooth-size discrepancies among different occlusion groups of southern Chinese children. Am J Orthod Dentofac Orthop 120: 556-558, 2001

8. Araujo E and Souki M. Bolton anterior tooth size discrepancies among different malocclusion groups. Angle orthod 73: $307-$ 313, 2003

9. Proffit WR, Fields Jr HW and Sarver DM. Contemporary orthodontics: Elsevier Health Sciences, Philadelphia, USA, 2006

10. Crosby DR and Alexander CG. The occurrence of tooth size discrepancies among different malocclusion groups. Am J Orthod Dentofac Orthop 95: 457-461, 1989

11. Freeman JE, Maskeroni A and Lorton L. Frequency of Bolton tooth-size discrepancies among orthodontic patients. Am J Orthod Dentofac Orthop 110: 24-27, 1996 
12. Alam MK, Hassan R, Mahmood Z and Haq ME. Determination and comparison of tooth size and tooth size ration in normal occlusion and different malocclusion groups. Int Med J 20: 462-465, 2013

13. Alam MK, Hossain MR, Islam MA. Reliability of Bolton Tooth Size Discrepancies in Bangladeshi population. Int Med J 20: 229-231, 2013

14. Alam MK, Shahid F, Kathiravan P, Basaruddin A and Khamis MF. Bolton tooth size ratio and its relation with arch widths, arch length and arch perimeter: A cone beam computed tomography (CBCT) study. Acta Odont Scand 72: 10471053, 2014

15. Graber LW, Vanarsdall Jr RL and Vig KW. Orthodontics: current principles and techniques: Elsevier Health Sciences; 2011 Philadelphia PA, USA

16. Paredes V, Gandia JL and Cibrian R. Do Bolton's ratios apply to a Spanish population? Am J Orthod Dentofac Orthop 129: 428-430, 2006

17. Stevens DR, Flores-Mir C, Nebbe B, Raboud DW, Heo G and Major PW. Validity, reliability, and reproducibility of plaster vs digital study models: comparison of peer assessment rating and Bolton analysis and their constituent measurements. Am J Orthod Dentofac Orthop 129: 794803, 2006

18. Mullen SR, Martin CA, Ngan P and Gladwin M. Accuracy of space analysis with emodels and plaster models. Am J Orthod Dentofac Orthop 132: 346-352, 2007

19. Shahid F, Alam MK, Khamis MF, Muraoka R, Nakano K and Okafuji N. Validity and reliability of digital model measurements: A digital stereomicroscopic study. J Hard Tissue Biol 23: 439-444, 2014

20. Santoro M, Galkin S, Teredesai M, Nicolay OF and Cangialosi TJ. Comparison of measurements made on digital and plaster models. Am J Orthod Dentofac Orthop 124: 101-105, 2003

21. Sonbol HN, Al-Omari IK, Duaibis RB, Saleh MW and AlBitar ZB. A comparison between a new 2-dimensional digital on-screen tooth measurement method with direct measurements. Saudi Med J 32: 895-900, 2011

22. Shahid F, Alam MK, Khamis MF, Honda Y, Sugita Y and Maeda H. Geomorphometrics of Tooth Size and Arch Dimension Analysis by Conventional Digital Caliper and Digital Stereomicroscope to Establish Standard Norms for the Pakistani Population. J Hard Tissue Biol 24: 155 -168, 2015

23. Tarazona B, Llamas J, Cibrian R, Gandia J and Paredes V. A comparison between dental measurements taken from $\mathrm{CBCT}$ models and those taken from a Digital Method. Eur J Orthod 35: 1-6, 2013

24. Bolton WA. Disharmony In tooth size and its relation to the analysis and treatment of malocclusion. Angle Orthod 28:
113-130, 1958

25. Bolton WA. The clinical application of a tooth-size analysis. Am J Orthod 48: 504-529, 1962

26. Bennett JC. Orthodontic Treatment Mechanics and the Preadjusted Appliance: Mosby, Wolfe Pub, London, 1993

27. Uysal T, Sari Z, Basciftci FA and Memili B. Intermaxillary tooth size discrepancy and malocclusion: is there a relation? Angle orthod 75: 208-213, 2005

28. Endo T, Abe R, Kuroki H, Oka K and Shimooka S. Tooth size discrepancies among different malocclusions in a Japanese orthodontic population. Angle Orthod 78: 994-999, 2008

29. Vandenbroucke JP, Von Elm E, Altman D G, Gøtzsche PC, Mulrow CD, Pocock SJ and Egger M. Strengthening the reporting of observational studies in epidemiology (STROBE): Explanation and elaboration. Ann Intern Med 47: 163-194, 2007

30. Dupont WD and Plummer WDJr. Power and sample size calculations for studies involving linear regression. Control Clin Trials 19: 589-601, 1998

31. Houston WJ. The analysis of errors in orthodontic measurements. Am J Orthod 83: 382-390, 1983

32. Garino F and Garino G. Comparison of dental arch measurements between stone and digital casts. World J Orthod 3: 250-254, 2002

33. Grünheid T, Patel N, De Felippe NL, Wey A, Gaillard PR and Larson BE. Accuracy, reproducibility, and time efficiency of dental measurements using different technologies. Am J Orthod and Dentofac Orthop 145: 157164,2014

34. Khamis MF, Taylor JA and Malik SN, Townsend GC. Odontometric sex variation in Malaysians with application to sex prediction. Forensic Sci Int 234: 183 e1-183 e187, 2014

35. Karaman F. Use of diagonal teeth measurements in predicting gender in a Turkish population. J Forensic Sci 51: 630-635, 2006

36. Bailey E, Nelson G, Miller AJ, Andrews L and Johnson E. Predicting tooth-size discrepancy: A new formula utilizing revised landmarks and 3-dimensional laser scanning technology. Am J Orthod and Dentofac Orthop 143: 574585,2013

37. Malik SN, Alam MK, Khamis MF and Gothe P. Racial dimorphism in Indians and Malaysians based on tooth size. Int Med J 21: 31-33, 2014

38. Mihailidis S, Scriven G, Khamis M and Townsend G. Prevalence and patterning of maxillary premolar accessory ridges (MxPARs) in several human populations. Am J Phy Anthropol 152: 19-30, 2013 